\title{
Habitat Selection of Invasive Sika Deer Cervus nippon Living in a UK Lowland Heathland- Woodland-Grassland Mosaic: Implications for Habitat Conservation Management
}

\author{
Anita Diaz ${ }^{1^{*}}$, Sean Walls ${ }^{2}$, Debbie Whitmarsh ${ }^{1}$, Martin Smith $^{1}$ and lain Green ${ }^{1}$ \\ ${ }^{1}$ Department of Life and Environmental Sciences, Bournemouth University, Fern Barrow, Poole, \\ Dorset, BH12 5BB, UK. \\ ${ }^{2}$ Biotrack Ltd., The Old Courts, Worgret Rd, Wareham BH2O 4PL, UK.
}

\section{Authors' contributions}

This work was carried out in collaboration between all authors. Author AD designed the study, performed the bulk of the statistical analysis, wrote the protocol and wrote the first draft of the manuscript. Author SW led the ranges habitat analysis. Author DW carried out the field work in collaboration with author $A D$ and led the deer diet analysis. Authors MS and IG led the plant nutrient analysis. All authors read and approved the final manuscript.

Article Information

DOI: $10.9734 / J S R R / 2017 / 38579$

Editor(s):

(1) Masum A. Patwary, Geography and Environmental Science, Begum Rokeya University, Rangpur, Bangladesh. (2) Leszek Labedzki, Professor, Institute of Technology and Life Sciences, Kujawsko-Pomorski Research Centre, Poland.

Reviewers:

(1) Hamit Ayberk, Istanbul University, Turkey. (2) Muhammed Khairujjaman Mazumder, Assam University, India. Complete Peer review History: http://www.sciencedomain.org/review-history/22587

Original Research Article

Received $1^{\text {st }}$ December 2017

Accepted $29^{\text {th }}$ December 2017

Published $4^{\text {th }}$ January 2018

\begin{abstract}
Understanding the factors determining the choice and use of habitats by invasive species is key to the conservation management of habitats and may also enable species to be harnessed as conservation tools. Here we explore the habitat use of an invasive population of sika deer, Cervus nippon on internationally important heathland in a landscape of heathland, grassland and woodland in southern UK. We used radio telemetry to test two hypotheses 1) grasses form a major part of the diet of non-native UK sika deer throughout the year 2) deer select grassland habitats above other habitats available. Results showed that although grasses form a major part of their diet, the strongest habitat selection was for heathland, the habitat that offered the least nutrient reward but
\end{abstract}


which offered a source of roughage in the diet and some harbourage from human disturbance. This has implications for the conservation management of heathlands used by sika deer as it strongly indicates that heathland is a vulnerable habitat due to being favoured by sika deer but that its vulnerability can be reduced by coupling population control with targeted habitat management action such as increased disturbance or the removal of harbourage.

Keywords: Grazing ecology; habitat management; deer grazing impacts.

\section{INTRODUCTION}

The effective control of invasive species is a major concern in conservation management and this has led to an important focus in the scientific and practitioner literature on prevention and eradication where this is possible and the role of adaptive management in securing successful control where it is not [1,2] although see [3]. Successful control ideally requires understanding of both how to most effectively manage overall population size and of how to target specific control effort at protecting the most ecologically sensitive systems. Understanding the factors determining the choice and use of habitats by invasive species is key to the development of more locally targeted control and may also enable habitat managers to harness some already established invasive species as conservation tools. This is an option worth exploring given the growing evidence of ways that invasive species can facilitate native species [4-7].

Sika deer, Cervus nippon Temmick, 1838 are native to Japan and east Asia but have over the last one hundred years been introduced and become feral in a range of habitats across the world including New Zealand, the United States, mainland Europe, the Republic of Ireland and mainland Britain $[8,9,10]$. Ecological impacts of high densities on habitats of conservation value due to direct feeding or trampling effects include damage to heathlands, wetlands, saltmarsh and natural forests $[11,12,13]$. In addition, indirect effects have been recorded on the abundance of tree seed predators via impacts on seed productivity [14].

Despite this growing appreciation of the impact of sika deer on habitats of high conservation value, relatively little is known of how they use habitats outside of their natural range. However, research has significantly advanced understanding of how sika deer use habitats in their native range $[15,16]$ and this provides a basis for generating hypotheses about their use of non native habitats. Native populations of sika deer occur widely throughout Japan and are most commonly found in forests (either coniferous or deciduous) that contain open grassy clearings and forest floors that are also often dominated by grasses, particularly dwarf bamboo, which form a major part of the diet of sika deer in Japan [17]. Graminoids are particularly important in the more cool northern, or higher altitude parts of Japan where species of dwarf bamboo such as Sasa nippon, can form the majority of their diet throughout the year [18-22]. Sika deer are migratory in their native range and the availability of bamboo as winter forage is considered as an important variable controlling the altitudinal limits for sika deer distribution in Japan [23]. Sika deer living in more southern, temperate parts of Japan have access to, and feed on, a wider range of other food sources in addition to $S$. nippon including evergreen herbs, evergreen tree leaves and Quercus acorns [24-26]. Only in very low nutrient habitats, or when population densities of deer become high, does tree leaf litter appear to become an important source of food $[27,28]$.

Much of the research on sika deer living in nonnative environments agrees that they are generally found most frequently in forests and scrub but that grasses form a substantial part of the diet $[29,30,31,11]$. Consequently a general consensus from studies of sika deer living in both native and alien habitats is that grasses form an important part of their overall habitat requirement and so this will strongly influence their selection of, use of and consequent impact on use of non-native habitats. This important factor for conservation management of habitats used by sika deer has never been directly tested; a key limitation of findings from these previous studies based on transect data [31] is that it cannot directly test individual animal habitat selection from what is available within their individual home range. In this paper we address this issue by examining the diet of sika deer and by using radio tracking to test the extent to which individual feral sika deer use grasslands as opposed to other habitats 
available within their home ranges. We discuss implications for how the distribution of grasslands and other habitats in a landscape may influence its suitability for sika deer and what the consequences of this can be for conservation management decisions.

This paper tests the following specific hypotheses:

1) grasses form a major part of the diet of non-native UK sika deer throughout the year

2) sika deer select grassland habitats above other habitats available.

\section{METHODS}

\subsection{Study Site}

Arne RSPB reserve is located in Purbeck, Dorset, England on the western edge of Poole Harbour and covers approximately 535 ha. of a mosaic of heathland, saltmarsh, woodland and farmland (Fig. 1). Purbeck has one of the highest density of feral sika deer (Fig. 2) in England and range expansion is occurring into parts of Devon and Somerset [32]. The feral animals are descendants of deer that escaped in the early twentieth century from captive populations introduced to Brownsea Island in Poole Harbour and Hyde House, a few $\mathrm{Km}$ away from Arne [33,32]: Arne is a particular hotspot for sika deer and overall density has been estimated by RSPB surveys at over 1 deer ha $^{-1}$ during the time of this study.

\subsection{Diet Analysis}

Rumen samples of healthy, adult deer were obtained by stalkers during routine winter culling operations (October - March). Samples were obtained from a total of 20 hinds and 5 stags and frozen immediately after collection. Each rumen sample was thawed completely just prior to preparation for analysis and $250 \mathrm{ml}$ of defrosted rumen sample was washed in a $2 \mathrm{~mm}$
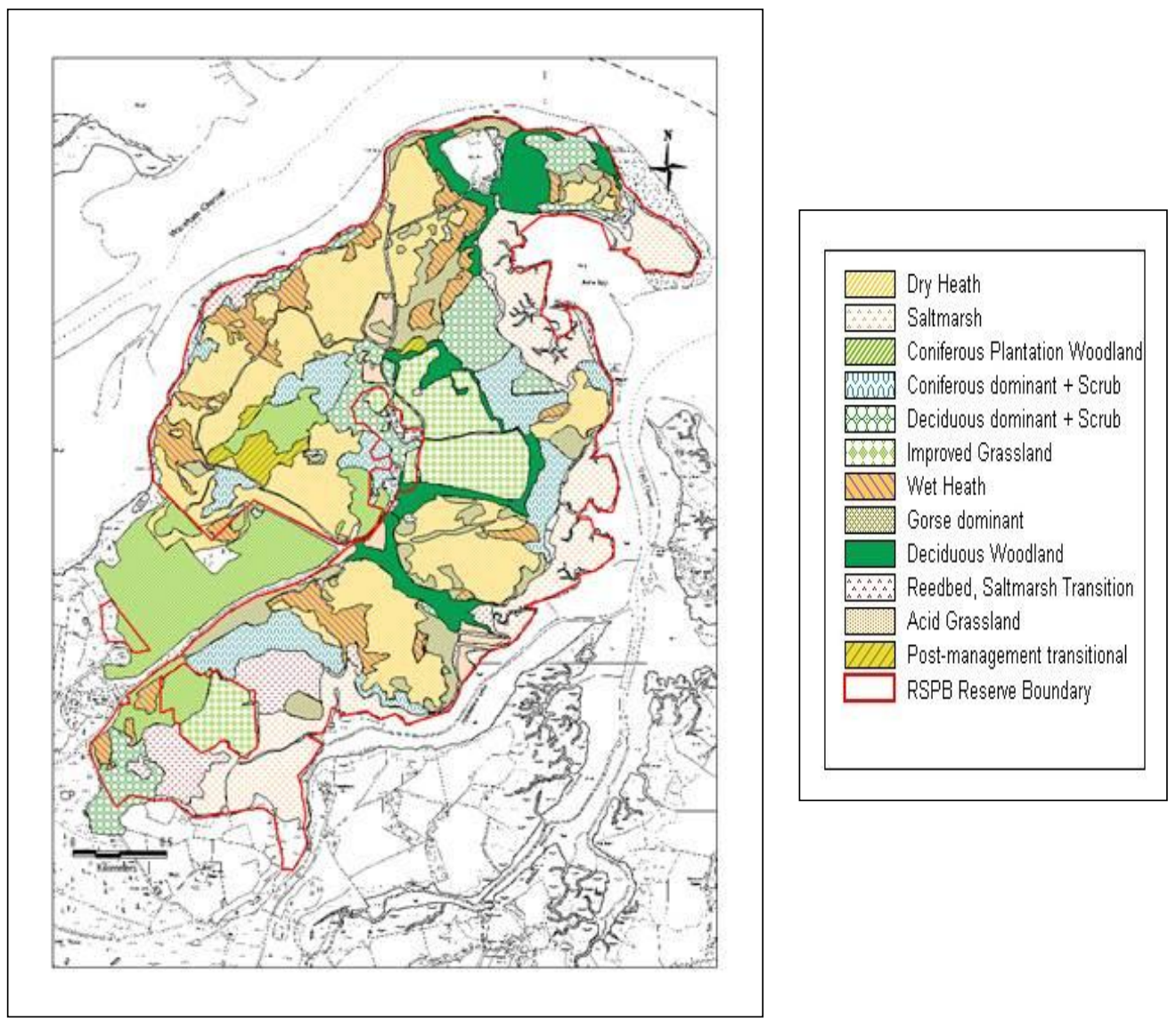

Fig. 1. Insert map of the study site at Arne showing the distribution of the major habitat types 

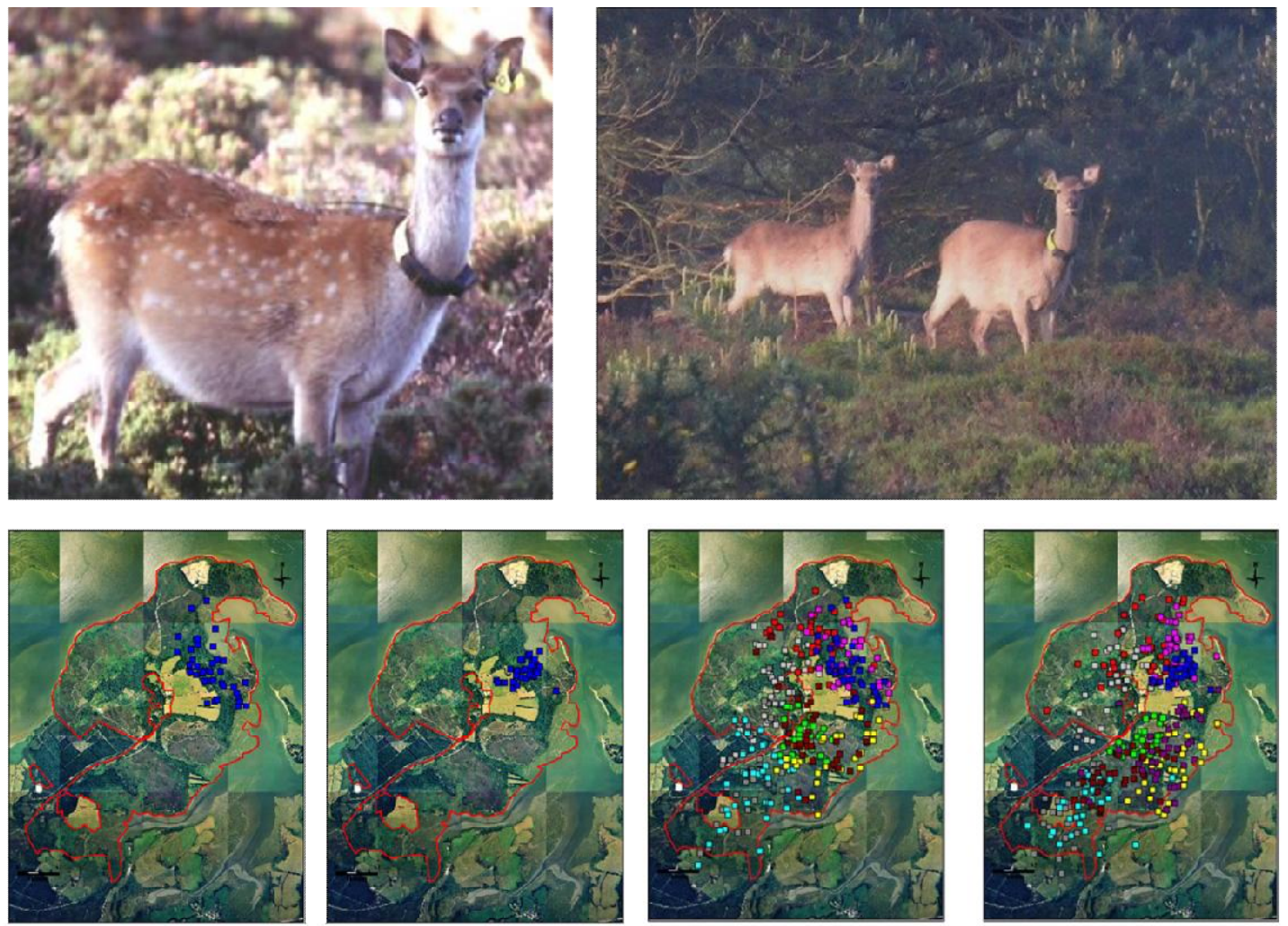

Fig. 2. The top photos show a collared adult female (hind) in the summer and winter with her calf. Collared hinds reproduced yearly and in all other ways behaved and interacted normally with other deer throughout the study period

brass sieve. The particles remaining in the sieve were sub-sampled to produce two random $10 \mathrm{ml}$ units of epidermal fragments. As some of the plant matter was in an advanced stage of digestion, it was not possible to identify all of the individual species present. Therefore, food types were allocated into the following general categories: forbs, grasses, ericoids (Calluna vulgaris, Erica tetralix, E. cinerea and E. cilliaris); gorse (Ulex europaeus and U. minor); holly (Ilex aquifolium) and ivy (Hedera helix); deciduous leaves; coniferous leaves; bark. Samples were spread in a petri dish and fragments counted under 10x magnification to give a mean number of fragments of each plant group per $\mathrm{ml}$ of rumen sample. All counted fragments were placed in separate containers to build up pure subsamples of each plant group found in the diet. A $10 \mathrm{ml}$ sub-sample was then taken of each of these monosamples and the number of fragments per $\mathrm{ml}$ of each monosample was determined by also counting using 10x magnification. The percentage volume of each food species present in the rumen sample was then calculated by dividing the number of fragments for each plant type present in $1 \mathrm{ml}$ of rumen mix with the number of fragments present in $1 \mathrm{ml}$ of its monosample and then multiplying this number by 100 .

To analyse diet change through the year, fifty faecal pellets were collected per month during 2005 and 2006. Only pellets large enough to be from mature animals were collected but it was not possible to distinguish pellets from hinds from those from stags so they were considered together. Only fresh pellets were collected. They were collected from across the study site with only one pellet collected from each group of pellets found. Pellets were frozen on day of collection to prevent decomposition of the epidermal fragments. Each pellet was analysed by first breaking open and softening the pellet in $2 \% \mathrm{NaOH}$ for three days. The pellet mixture was then neutralised by adding drop of $40 \%$ acetic acid and the contents of the beaker were then transferred to the mesh of a $0.5 \mathrm{~mm}$ sieve 
and washed with running water. The particles remaining in the sieve were transferred into 10 $\mathrm{ml}$ of $\mathrm{NaClO}$ in $90 \mathrm{ml}$ distilled water for 30 minutes to separate and clear the epidermal fragments. The epidermal fragments were then centrifuged for 2 minutes at $3000 \mathrm{rpm}$ (Haraeus Megafuge 1.0) after which the supernatant was poured off. Three random sub-sampled drops of the epidermal fragments were mounted on a microscope slides. Epidermal fragments were identified by comparison against plant species held in an epidermal library created from fresh plant samples from Arne. As some grass species were difficult to distinguish reliably, a decision was taken to group all grasses. The plants identified to species were chosen on the basis that they were abundant on the study site, potential food plants and could be unambiguously distinguished. They were: Betula pendula, Calluna vulgaris, Erica cinerea, Erica tetralix, Halimionie portulacoides and Trifolium repens. Species were scored as either present or absent in each of the faecal pellets to obtain a frequency of occurrence. The abundance of each species within a pellet was not measured as this can be greatly influenced by the relative digestibility of different plant species.

\subsection{Nutrient Quality of Food Plants}

The concentration of nutrients in leaf material available to sika deer was measured in high summer (July) for the most abundant species accessible to sika deer within grassland, heathland and woodland habitats. The species were: Agrostis capillaris, Agrostis curtisii, Betula pendula, Calluna vulgaris, Dactylis glomerata, Erica cinerea, Erica tetralix, Halimione portulacoides, Holcus lanatus, Lolium perenne, Molina caerulea, Puccinellia maritima, Spartina anglica and Trifolium repens. Five samples of each species (approximately $5 \mathrm{~g}$ fresh weight) were collected from random locations across the study site. Plant samples were washed in $0.01 \%$ detergent solution and rinsed twice in distilled water. Washed samples were dried to constant weight at $60^{\circ} \mathrm{C}$ before homogenisation in a rotary mill. Elemental nutrients other than $\mathrm{N}$ and $\mathrm{C}$ were extracted from $0.25 \mathrm{~g}$ sub-samples of the milled plant material via digestion in $10 \mathrm{ml}$ of $69 \%$ analytical grade nitric acid [34]. Quantification of element concentrations in digests were determined by Inductively Coupled Plasma - Optical Emission Spectrometry (Vista Pro, Varian Inc., Australia). Duplicate determinations were made for each plant sample. Total $\mathrm{N}$ and $\mathrm{C}$ concentrations in plant samples were determined using an Elemental Analyser (EA 1112, Thermo Finnigan inc. Italy). Prior to $\mathrm{N}$ and $\mathrm{C}$ analysis, a sub-sample of plant material was ground into a fine powder in a Retsch MM200 mixer mill (Retsch GmbH \& Co). Peak integration was standardised by the combustion of acetanilide (Elemental Microanalysis, Okehampton Devon, UK) and three replicate determinations were performed for each plant sample.

\subsection{Habitat Selection within Home Ranges}

Twenty mature female sika deer (hinds) were captured using drop nets during the winter of 2004 and 2005 and fitted with radio collars supplied by Biotrack Ltd. (Dorset, UK). The deer capture was supervised by a fully qualified deer manager, who was the deer manager at Arne during the time of this study. Observations on the hinds indicated that all animals remained healthy following collaring and appeared to interact normally with other sika deer (they herded with other sika deer and bore young as normal). It was decided not to include males in the study because i) the females are of more importance to deer managers as their numbers determine population growth and they teach their calves where to forage ii) there are considerably greater animal welfare concerns with collaring males (stags) as their necks swell during the mating season so the collars need to be very reliably expandable and contractible for a three year study. Signals from the collars were detected using a TR-4 Receiver (Telonics, Arizona, USA) and 3-element Yagi Antenna. The range size and habitat occupancy of each hind was recorded in 2005 and 2006 during the following months: February (winter) when food resources were lowest; May (spring) during breeding; July (summer) when food was more abundant and days were longer; October (autumn) during the rut. An incremental analysis of a pilot study when at least 50 locations were collected for each animal showed that range size did not increase after 30 locations; i.e. the individual had visited all areas it was likely to in that season. Therefore every season, each sika deer was found to within $100 \mathrm{~m}, 30$ times at random times during the day and night with the restriction that successive recording times were never less than six hours apart to avoid any autocorrelation. For each point, the location of the hind was established by triangulation from at least three (often 5) separate sampling 
positions; Sampling positions were spread across the reserve and travel between positions was made mostly by vehicle to maximise speed and minimise disturbance to the deer. Hind locations were always calculated before leaving the field to ensure that triangulation error areas were small.

\subsection{Data Analysis}

Analyses of the data on diet and nutrient quality of food plants were carried out using SPSS version 15. Data were non-parametric and so the Mann Whitney $U$ test was used to compare means for two independent samples, the Wilkoxen signed ranks test was used to compare means for two paired samples, the Friedman test was used to compare means for more than two paired samples and the Kruskal Wallis test was used to compare means for more than two independent samples.

Analysis of radiotracking data was accomplished using Ranges8 [35] The Minimum Convex Polygon (MCP) home range was calculated for each collection of locations. Other home range models were investigated, but due to the even spread of locations and absence of outliers no other home range model improved the fit to the locations and therefore the MCP was used as it has least assumptions. Habitat selection is defined as the relationship between what an animal uses compared to what is available [36] thus Ranges8 was then used to calculate: i) the habitat content of the home ranges to represent what was available to each deer; it was reasonable to assume that the deer could reach all parts of the home range; ii) the habitat within 50 metres (half the resolution) of each location, to represent what the deer was USING within each range; i.e. where it was spending time rather than just passing through on the way to resources. Compos Analysis 6.2 plus (www.smithecology.com) was then used to:

1) compare whether one habitat was selected over another habitat (t-tests),

2) rank the habitats from most to least selected; the most selected was the habitat that was most commonly selected in each bilateral habitat test as in point 1.

3) test the significance of the ranking (Wilks' Lambda ). Randomized $P$ was used for the test as there was no guarantee that the distribution of log-ratio differences were multivariate normal [37].

\section{RESULTS}

\subsection{Diet Analysis}

Significant differences were found between vegetation types in their frequency of occurrence in rumen contents collected from deer during October-March (Fig. 3, Friedman test Chi square $=110.0, P<0.001)$. Grasses formed a particularly large part of the rumen volumes with ericaceous species and deciduous leaves, twigs and buds being the second and third most prevalent components. The volume of grass in the rumens was significantly greater than either the ericaceous or deciduous material (Wilkoxen Signed Ranks test $Z=2.61, P<0.001$ and $Z=3.70, \quad P<0.001$ ) respectively. No significant differences were found between hinds and stags for consumption of any food category (Mann Whitney $U$ tests all $P>0.005$ ).

Analysis of faecal samples also indicated that grasses were an important part of the diet throughout the year. (Fig. 4).

\subsection{Plant Nutrient Analysis}

Significant differences between species were found in the nutrient content of leaf tissue for all nutrients tested (Table 1. Kruskal Wallis $\mathrm{H}>40$, $\mathrm{P}<0.001$ for all nutrients). The highest concentration of tissue nitrogen $(\mathrm{N})$ were found in the mesotrophic plants Trifolium repens, Lolium perenne and Dactylis glomerata. The leaves of Betula pendula also contained high $\mathrm{N}$ concentrations while lowest $\mathrm{N}$ concentrations were found in the ericaceous species, Calluna vulgaris, Erica tetralix and Erica cinerea. Intermediate concentrations of $\mathrm{N}$ were found in the dominant grasses of acid grassland (Agrostis capillaris) and saltmarsh (Spartina anglica). The pattern of relative concentration of $P$ between plant species was similar to that for $\mathrm{N}$ with concentrations beginning highest in the mesotrophic grassland species but this was not the case for the other elements investigated. For example, concentrations of potassium and magnesium were highest in Holcus lanatus, concentration of calcium was highest in Trifolium repens, concentrations of zinc was highest in $B$. pendula and concentrations of iron and copper were highest in the saltmarsh species, Puccinellia maritima and Halimione portulacoides respectively. The ericaceous species and the wet heathland grass Molinia caerulea had among the lowest concentrations of all nutrients out of the plant species surveyed. 


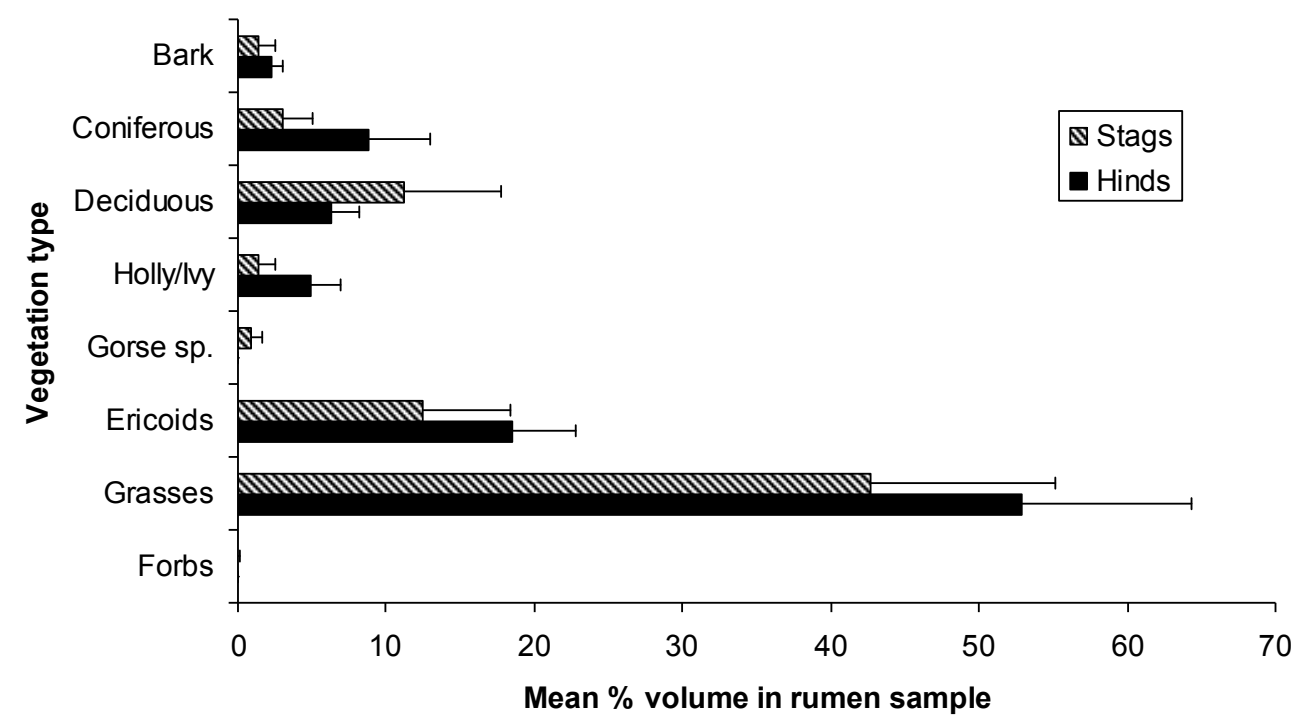

Fig. 3. Mean percentage volume of different plant species in the rumen samples of stags and hinds at Arne. Samples were obtained from a total of 20 hinds and 5 stags during routine management culls. Defrosted samples were washed in a $2 \mathrm{~mm}$ brass sieve to obtain epidermal fragments which were then identified down to major types of vegetation

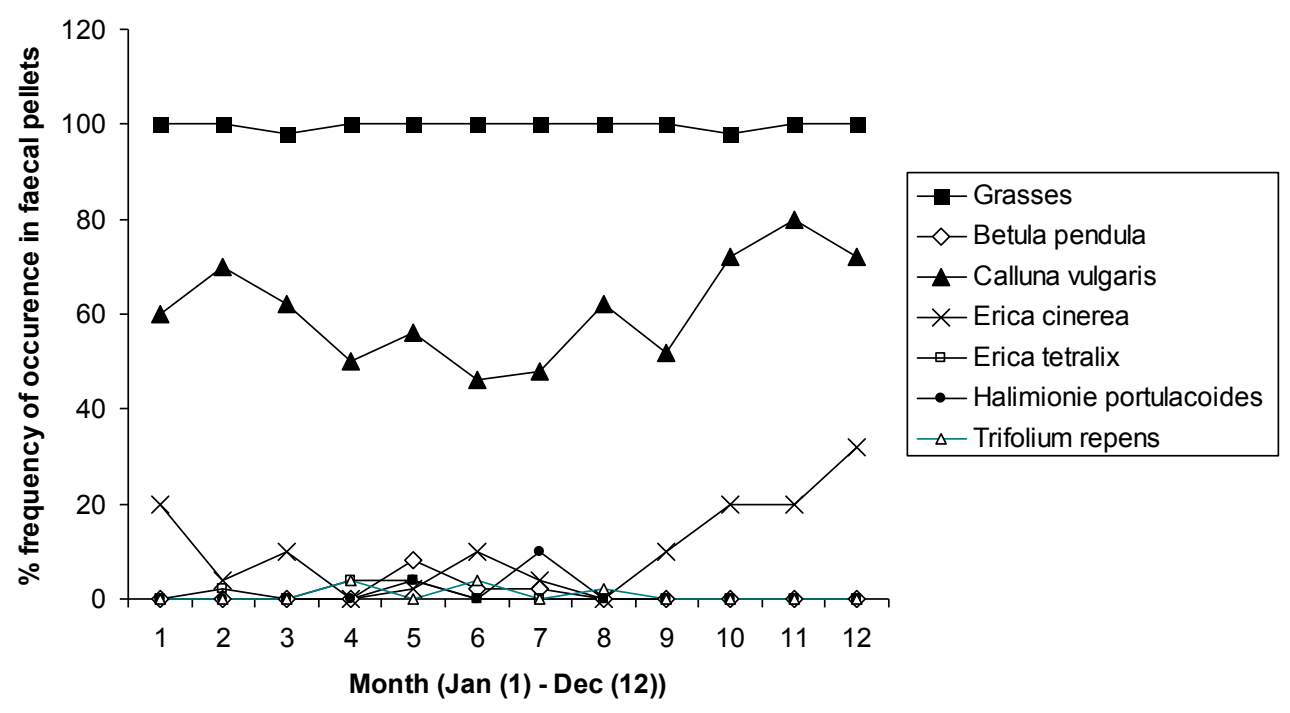

Fig. 4. Seasonal change in percentage of sika deer faeces found to contain epidermal fragments of a range of plant species. 50 faecal pellets were collected per month. Only fresh pellets large enough to be from mature animals were collected. They were collected from across the study site with only one pellet collected from each group of pellets found

\subsection{Habitat Selection within Home and 2006 (Fig. 5). The same individual deer Ranges were tracked during 2005 and 2006 and so compositional analysis for habitat selection was \\ Availability of habitats within the home ranges was dominated by dry heathland in both 2005 run separately for each season of each year to avoid psuedoreplication (Table 2). Habitat}


selection appeared to change little between years, but much more strongly between seasons. More selection was apparent in February and October compared to May and July, with no one habitat being most selected throughout the year. In both years dry heathland was most selected in February and October, whereas wet heathland was more important in May. In July the order ranking varied between years, but was only significant for 2006 when again wet heathland was most selected. In October there was slight variation between years but both had significant ranking and the top three habitats were dry heathland, improved grassland and gorse scrub.

Dry heathland, improved grassland and gorse scrub, together with wet heathland, all seemed to be selected to some degree in all seasons. Therefore their change in use over the seasons was investigated for the year 2006 that showed the most significant ranking (Fig. 6). Only wet heathland use showed a significant change by season (Fig. 6h). The availability of wet heath (Fig. 6g) did not change by season, but during May there was much greater use of wet heathland. Dry heathland use was greater than the availability in all seasons, although there was a distinct drop in use and availability during July, suggesting a subtle range shift.

\section{DISCUSSION}

Understanding the reasons why deer select particular habitats is important for determining their key ecological interactions and vital for the effective management of wild deer at a landscape scale. One of the major factors affecting the suitability of habitats for deer is food availability and grazing/browsing is a key way in which deer modify the habitats they occupy. Our study of the diet of sika deer living in a mosaic of grassland, heathland and woodland habitats in Dorset found that grasses were a major part of their diet throughout the year with the second most abundant component being the ericaceous shrub Calluna vulgaris. Tree leaves and twigs together formed the third main part of their diet. Rumen samples were only available through the winter culling period but results from faecal analysis indicated that there were some small seasonal differences in diet; in particular the ericoids $C$. vulgaris and Erica cinerea were consumed more in the winter months. Comparison of our findings with those of the only previously published research on the diet of feral sika in Britain [30] indicate that the diet of the deer in our study is intermediate between sika deer living in conifer plantations in Scotland and in Wareham Forest Dorset, UK where their diet was dominated by

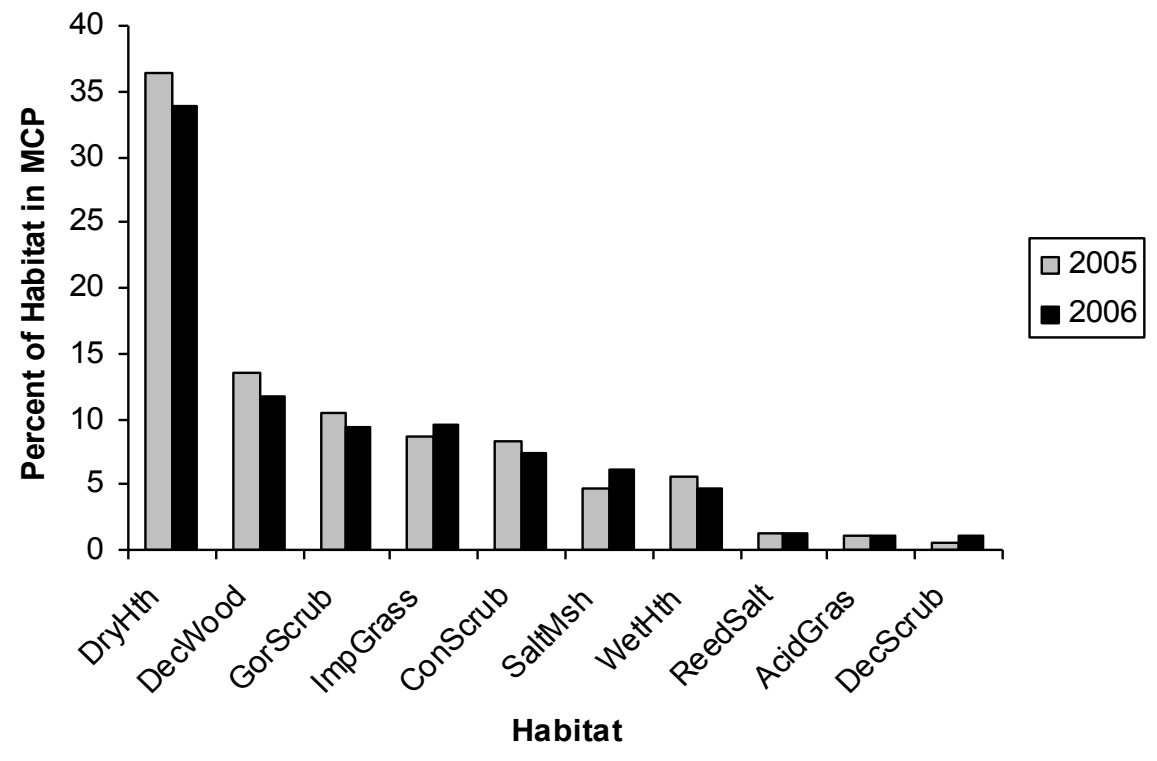

Fig. 5. Median percentage area of habitat available within the home range of sika deer hinds in 2005 and 2006. MCP is the Minimum Convex Polygon home range and was calculated using Ranges8. Availability of habitats within the home ranges was dominated by dry heathland in both 2005 and 2006 
grass with some heather and the more varied diet of deer living in the New Forest, Hampshire that had access to greater availability of forbs and of deciduous tree leaves and fruits (Quercus acorns and Fagus beech mast). Our study found no sexual differences in diet but was only able to examine this during the winter months when cull samples were available. Studies of Japanese populations living in nutrient rich, temperate habitats that have examined differences throughout the year have found conflicting results. For example, one study found considerable overlap between the diets of stags, hinds and calves [38] while two other found differences; [39] found that stags fed on more nutritious food than hinds when growing antlers and in the winter and [19]'found that stags consumed more seeds and fruit than hinds in the autumn.

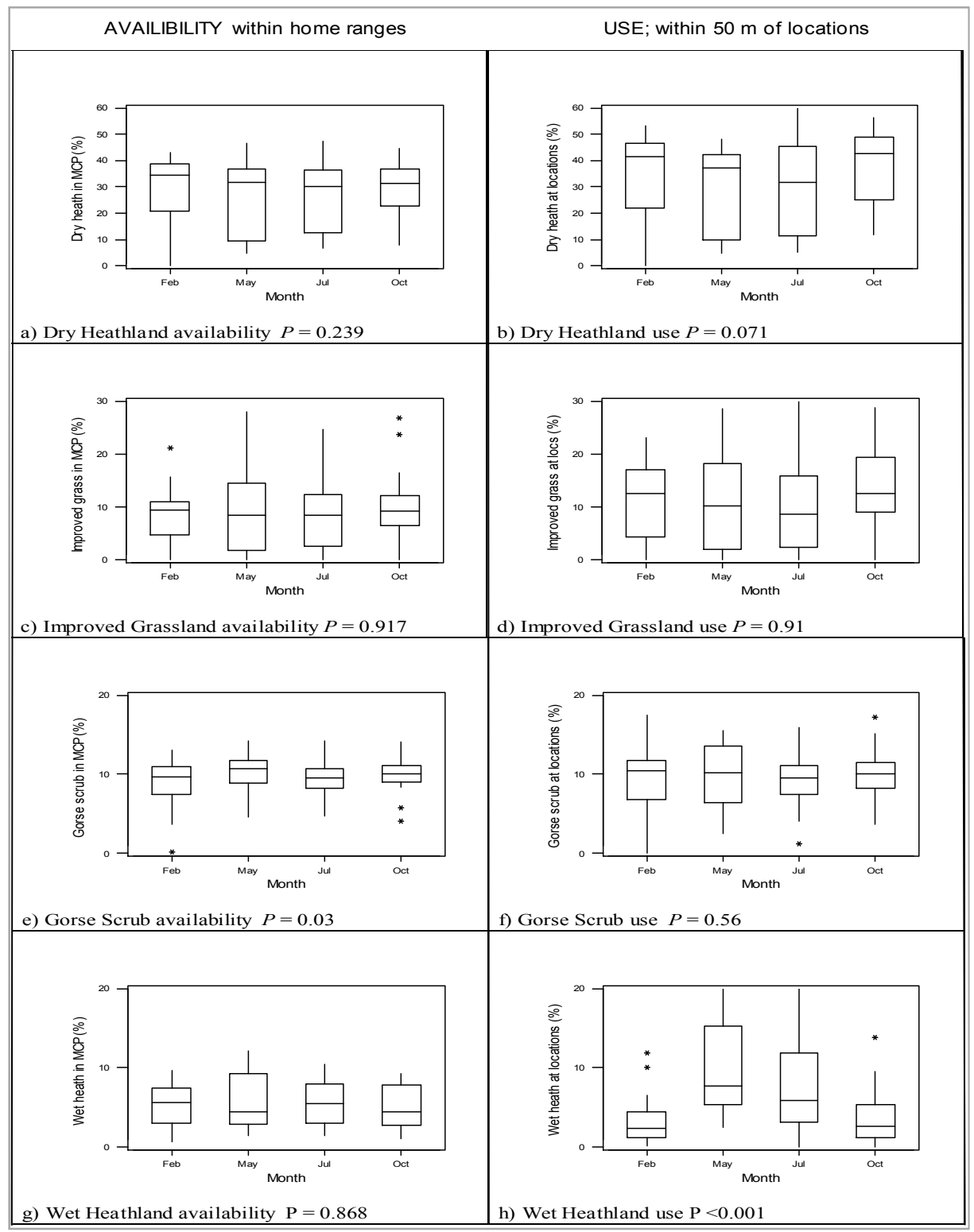

Fig. 6. The availability and use of habitats by season, and Kruskal-Wallis test of whether it changes significantly by season. Only wet heathland was used significantly differently across seasons; it was used very little during the winter but a lot in May when the grass is fresh growing (Fig. 6h). Dry heathland was used most heavily compared to availability across all seasons 
Table 1. Summer nutrient concentrations (ppm) of leaf tissue from a range of plant species. Results show mean and Standard Error (SEM) from five samples of each species (approximately $\mathbf{5} \mathbf{g}$ fresh weight) collected from random locations across the study site

\begin{tabular}{|c|c|c|c|c|c|c|c|c|c|c|c|c|c|}
\hline \multirow[t]{2}{*}{ Species } & & \multicolumn{12}{|c|}{ Nutrient concentrations (ppm) } \\
\hline & & Al & $\mathbf{C}$ & $\mathrm{Ca}$ & $\mathrm{Cu}$ & $\mathrm{Fe}$ & $\mathbf{K}$ & Mg & Mn & $\mathbf{N}$ & $\mathbf{P}$ & $\mathbf{S}$ & Zn \\
\hline \multirow[t]{2}{*}{ Agrostis capillaris } & mean & 10.8 & 42.3 & 3408.1 & 4.5 & 71.5 & 9203.6 & 1864.6 & 33.9 & 1.4 & 2145.3 & 1144.8 & 38.7 \\
\hline & SEM & 1.35 & 0.56 & 574.22 & 0.34 & 6.33 & 883.97 & 261.87 & 4.63 & 0.15 & 195.93 & 73.95 & 7.73 \\
\hline \multirow[t]{2}{*}{ Agrostis curtisii } & mean & 12.4 & 42.3 & 1406.6 & 10.3 & 79.0 & 8660.6 & 913.7 & 25.1 & 1.5 & 739.3 & 1441.7 & 14.2 \\
\hline & SEM & 4.06 & 0.67 & 91.91 & 3.01 & 9.70 & 1274.08 & 90.23 & 1.74 & 0.15 & 84.45 & 100.75 & 1.16 \\
\hline \multirow[t]{2}{*}{ Betula pendula } & mean & 16.9 & 47.4 & 7122.2 & 4.7 & 85.4 & 5645.6 & 4934.4 & 23.2 & 2.2 & 1302.7 & 1298.6 & 215.0 \\
\hline & SEM & 2.33 & 1.09 & 1116.54 & 0.43 & 7.25 & 1017.66 & 323.92 & 5.56 & 0.06 & 163.17 & 79.13 & 44.84 \\
\hline \multirow[t]{2}{*}{ Calluna vulgaris } & mean & 23.9 & 49.6 & 3871.6 & 8.0 & 76.8 & 4536.1 & 2186.6 & 15.0 & 1.4 & 892.1 & 1048.4 & 23.7 \\
\hline & SEM & 1.63 & 0.80 & 247.48 & 1.74 & 11.09 & 331.96 & 181.19 & 2.29 & 0.06 & 70.32 & 43.05 & 2.56 \\
\hline \multirow[t]{2}{*}{ Dactylis glomerata } & mean & 16.8 & 43.9 & 4303.5 & 7.4 & 95.4 & 17201.6 & 2183.3 & 9.1 & 2.1 & 2379.4 & 1869.7 & 26.7 \\
\hline & SEM & 3.79 & 1.50 & 600.67 & 0.89 & 17.53 & 1457.29 & 178.12 & 2.92 & 0.24 & 230.99 & 212.21 & 2.58 \\
\hline \multirow[t]{2}{*}{ Erica cinerea } & mean & 19.4 & 51.3 & 2669.9 & 5.2 & 54.3 & 3912.4 & 2360.7 & 5.9 & 1.1 & 564.5 & 1008.4 & 19.8 \\
\hline & SEM & 2.24 & 0.66 & 319.27 & 0.74 & 6.74 & 461.43 & 246.31 & 1.01 & 0.02 & 103.07 & 79.17 & 3.63 \\
\hline \multirow[t]{2}{*}{ Erica tetralix } & mean & 20.8 & 52.9 & 3683.3 & 6.2 & 81.9 & 2765.2 & 1469.8 & 18.9 & 1.1 & 393.6 & 1068.8 & 23.1 \\
\hline & SEM & 2.64 & 0.72 & 440.72 & 0.92 & 15.71 & 361.09 & 172.96 & 2.70 & 0.02 & 61.19 & 125.75 & 3.43 \\
\hline \multirow{2}{*}{ Halimione portulacoides } & mean & 38.7 & 29.3 & 5641.2 & 24.6 & 231.2 & 16351.4 & 2352.1 & 19.3 & 1.6 & 2391.3 & 1924.0 & 46.3 \\
\hline & SEM & 7.62 & 1.46 & 1492.04 & 11.89 & 85.94 & 1603.22 & 259.96 & 7.08 & 0.08 & 191.19 & 92.31 & 18.06 \\
\hline \multirow[t]{2}{*}{ Holcus lanatus } & mean & 58.8 & 41.3 & 6120.7 & 3.7 & 245.8 & 20901.8 & 13309.6 & 1.2 & 2.0 & 1478.1 & 5161.4 & 46.1 \\
\hline & SEM & 17.66 & 0.85 & 494.68 & 0.78 & 77.62 & 861.93 & 1310.43 & 0.33 & 0.15 & 103.16 & 482.99 & 15.59 \\
\hline \multirow[t]{2}{*}{ Lolium perenne } & mean & 112.4 & 39.3 & 6911.7 & 12.4 & 356.2 & 16761.3 & 1980.3 & 2.6 & 2.4 & 3819.8 & 2732.8 & 28.4 \\
\hline & SEM & 32.00 & 0.86 & 1128.57 & 3.19 & 118.56 & 946.93 & 70.98 & 0.69 & 0.16 & 219.22 & 201.56 & 4.17 \\
\hline \multirow[t]{2}{*}{ Molina caerulea } & mean & 8.5 & 43.0 & 1570.7 & 3.9 & 64.4 & 6464.7 & 1545.7 & 18.5 & 1.6 & 594.8 & 1312.9 & 38.1 \\
\hline & SEM & 1.38 & 0.69 & 212.19 & 0.31 & 5.23 & 599.29 & 90.08 & 6.08 & 0.11 & 85.29 & 131.33 & 4.50 \\
\hline \multirow[t]{2}{*}{ Puccinellia maritima } & mean & 297.6 & 39.5 & 1703.2 & 6.0 & 1054.7 & 13398.2 & 3144.0 & 2.6 & 1.9 & 1916.2 & 2207.3 & 15.0 \\
\hline & SEM & 51.42 & 1.26 & 87.60 & 1.07 & 182.92 & 1422.00 & 367.97 & 0.39 & 0.04 & 161.78 & 150.51 & 1.02 \\
\hline \multirow[t]{2}{*}{ Spartina anglica } & mean & 17.2 & 41.2 & 2265.9 & 3.0 & 86.7 & 10782.3 & 5353.5 & 3.9 & 1.4 & 1932.1 & 5312.8 & 21.0 \\
\hline & SEM & 1.33 & 0.90 & 274.17 & 0.12 & 9.07 & 312.55 & 396.80 & 0.41 & 0.05 & 74.72 & 399.73 & 2.01 \\
\hline \multirow[t]{2}{*}{ Trifolium repens } & mean & 32.1 & 42.5 & 16282.8 & 8.3 & 167.5 & 12863.1 & 2931.6 & 2.4 & 4.1 & 3070.5 & 1691.7 & 28.5 \\
\hline & SEM & 11.07 & 1.32 & 2241.85 & 0.69 & 46.30 & 798.68 & 198.04 & 0.19 & 0.34 & 254.27 & 117.19 & 1.82 \\
\hline
\end{tabular}


Table 2. Compositional analysis of habitat selection by sika deer hinds for each season individually. Ranking shows the habitats ordered from most to least selected, $n$ is the number of deer used in each analysis, Wilk's lambda is the test statistic for the overall selection with a MANOVA which gives the overall significance of the model, Chi is the test statistic for generating $P$ which denotes the probability of the overall habitat

order being significant. The symbol $\gg>$ indicates that the habitat on the left is significantly more selected than the adjacent habitat on the right; > indicates the habitat on the left has a higher (but not significant) selection value than the immediate right and $=$ indicates no significant difference in ranking between the habitats either side

\begin{tabular}{|c|c|c|c|c|c|c|c|}
\hline $\mathbf{n}$ & Season & Year & Lambda & Chi & $\mathbf{P}$ & Prand & Ranking \\
\hline 33 & February & both & 0.1444 & 65.8 & 0.0000 & 0.001 & $\begin{array}{l}\text { DryHth }>>>\text { GorScrub>ImpGrass>ConScrub }>\text { DecWood }>\text { SaltMsh }>\text { WetHth }>\text { DecScrub }> \\
\text { AcidGras }>\text { ReedSalt }\end{array}$ \\
\hline 18 & & 2005 & 0.0988 & 41.7 & 0.0000 & 0.001 & $\begin{array}{l}\text { DryHth }>>>\text { ConScrub }>\text { GorScrub }>\text { ImpGrass }>\text { DecWood }>\text { SaltMsh }>\text { WetHth }>\text { ReedSalt }>\text { D } \\
\text { ecScrub }>\text { AcidGras }\end{array}$ \\
\hline 15 & & 2006 & 0.0822 & 37.5 & 0.0000 & 0.007 & $\begin{array}{l}\text { DryHth }>\text { DecWood }>\text { GorScrub }>\text { ImpGrass }>\text { SaltMsh }>\text { ConScrub }>\text { DecScrub }>\text { WetHth }>\text { Aci } \\
\text { dGras }>\text { ReedSalt }\end{array}$ \\
\hline 34 & May & both & 0.1397 & 66.9 & 0.0000 & 0.001 & $\begin{array}{l}\text { WetHth }>>>\text { ImpGrass }>\text { DryHth }>\text { GorScrub }>\text { DecWood }>\text { AcidGras }>\text { ConScrub }>\text { SaltMsh }>R \\
\text { eedSalt }>\text { DecScrub }\end{array}$ \\
\hline 18 & & 2005 & 0.1828 & 30.6 & 0.0003 & 0.047 & $\begin{array}{l}\text { WetHth }>\text { ImpGrass }>\text { GorScrub }>\text { DryHth }>\text { AcidGras }>\text { DecWood }>\text { ConScrub }>\text { SaltMsh }>\text { Ree } \\
\text { dSalt }>\text { DecScrub }\end{array}$ \\
\hline 16 & & 2006 & 0.0417 & 50.8 & 0.0000 & 0.001 & $\begin{array}{l}\text { WetHth }>>>\text { DryHth }>\text { ImpGrass }>>>\text { GorScrub>ConScrub>DecWood }>\text { SaltMsh>AcidGras } \\
>>\text { ReedSalt }>\text { DecScrub }\end{array}$ \\
\hline 34 & July & both & 0.3294 & 37.8 & 0.0000 & 0.005 & $\begin{array}{l}\text { DryHth>SaltMsh>WetHth>DecWood }>\text { GorScrub }>\text { ImpGrass }>\text { ConScrub }>\text { ReedSalt }>\text { Dec } \\
\text { Scrub }>\text { AcidGras }\end{array}$ \\
\hline 18 & & 2005 & 0.2019 & 28.8 & 0.0007 & 0.063 & $\begin{array}{l}\text { ImpGrass }>\text { DryHth }>\text { SaltMsh=DecWood }=\text { GorScrub }>\text { WetHth }>\text { ConScrub }>\text { AcidGras }>\text { Ree } \\
\text { dSalt }>\text { DecScrub }\end{array}$ \\
\hline 16 & & 2006 & 0.1924 & 26.4 & 0.0018 & 0.078 & $\begin{array}{l}\text { WetHth }>\text { DecWood }>\text { DryHth }>\text { SaltMsh }>\text { GorScrub }>\text { ConScrub }>\text { ImpGrass }>\text { DecScrub }>\text { Re } \\
\text { edSalt }>\text { AcidGras }\end{array}$ \\
\hline 33 & October & both & 0.1139 & 71.7 & 0.0000 & 0.001 & $\begin{array}{l}\text { DryHth }>\text { ImpGrass }>\text { GorScrub }>\text { DecWood }>\text { ConScrub }>\text { WetHth }>\text { SaltMsh=DecScrub }=\text { Aci } \\
\text { dGras }>\text { ReedSalt }\end{array}$ \\
\hline 17 & & 2005 & 0.0540 & 49.6 & 0.0000 & 0.001 & $\begin{array}{l}\text { DryHth>ImpGrass>>>GorScrub>ConScrub>DecWood>AcidGras>SaltMsh>DecScrub } \\
>\text { WetHth>ReedSalt }\end{array}$ \\
\hline 16 & & 2006 & 0.1072 & 35.7 & 0.0000 & 0.006 & $\begin{array}{l}\text { DryHth }>\text { ImpGrass }>\text { GorScrub }>\text { DecWood }>\text { WetHth }>\text { ConScrub }>\text { DecScrub }>\text { SaltMsh }>\text { Aci } \\
\text { dGras }>\text { ReedSalt }\end{array}$ \\
\hline
\end{tabular}


A comprehensive assessment of the overall nutritional value of food consumed by a given animal at a given point requires a consideration of many factors. For example, although it is generally agreed that the single most important nutrient that deer obtain from plants is nitrogen for the production of protein $[40,19]$, deer need a wide range of other nutrients [41] and requirements for these will change over time. Also the actual nutritional quality of food consumed will depend on factors including: nutrient concentrations of the plant tissue, physical and chemical factors of the plant tissue such as lignin and tannins that affects its digestibility [42] and seasonal changes in the rumen microbes of the deer $[43,44]$. Our study assessed plant tissue nutrient concentration during the peak plant growth season to obtain a basic comparison of this factor across plant species and found that by feeding on grasses, sika deer select the most nitrogen rich sources, particularly when consuming mesotrophic grasses. Another advantage of feeding on grasses is that cervids are known to have greater foraging efficiencies on grasslands than in other habitats because the food is available as a concentrated, low growing mat [45]. Indeed, a study of sika deer in Japan has found that the greater foraging efficiencies on grasses growing on mires may explain why deer selected these over forest forage despite the lower nitrogen concentrations in the plant tissues [17] .

Combining the influence of $\mathrm{N}$ levels, digestibility and foraging efficiencies, the deer in our study would be predicted to maximise their rate of uptake of nitrogen by feeding on mesotrophic grasses. It would also be predicted that nitrogen uptake would be moderate from feeding on all other non-mesotrophic grasses studied (low $\mathrm{N}$ content but high digestibility and foraging efficiency) and on birch leaves (high $\mathrm{N}$ content, low digestibility and feeding efficiency). Lowest rates of uptake of nitrogen would be predicted to be achieved by feeding on ericaceous species (low $\mathrm{N}$ content, low digestibility and only moderate feeding efficiency). The ericaceous species also had low concentrations of all other nutrients except carbon and so the most important contribution made by them to the diet of the sika deer would appear to be the provision of roughage. This may be an important reason why sika deer feed on ericaceous material and it has similarly been proposed that sika deer strip bark for reasons such as roughage and balancing $\mathrm{K} /(\mathrm{Ca}+\mathrm{Mg})$ levels in the diet rather than for bulk nutrient acquisition $[46,47]$.

In general, we found that mature hinds positively selected dry heath more strongly than they did any other habitat. The only exception to this was that in the spring (May) wet heath was generally the most strongly selected habitat. Wet heath may have been selected in the spring as it provided the deer with two important resources at this time, abundant fresh soft growth of the grass Molinia caerulea and cover for less mobile calves. Fresh growth of $M$. caerulea is known to be readily consumed by Cervus elaphus [48,49] and was observed to also be strongly grazed by $C$. nippon in our study despite its relatively low nitrogen content. Signs of grazing of $M$. caerulea were particularly prevalent in areas where sika deer hid their calves and it may be that hinds were selecting M. caerulea over other proximate food sources (predominantly Erica tetralix which is hairy so unpalatable as well as low in nutrient concentrations) rather than journey far from young calves. Such grazing of $M$. caerulea usefully avoids its dominance of $E$. tetralix which is the most important larval food plant of a high conservation value species, the silver studded blue butterfly, Plebeius argus.

The strong selection for dry heath by sika deer in our study suggests that other factors may be important in addition to the gains in roughage and mineral balancing achieved through browsing ericaceous vegetation. The deer in our study have no natural predators but the area has many tourist visitors particularly in the immediate vicinity of the mesotrophic grasslands and this may limit the effective availability of this habitat to them. It has been recorded that habitat use of sika deer may be influenced by disturbance from tourists [50] or by the tendency of deer to gather in larger groups in open habitats due to improved feeding efficiency and survival in the face of predation pressures [51,21]. Cover of dense coniferous forest surrounding open grassland has been suggested as an important habitat feature for native sika deer on Mt Ohdaigahara, Japan [52]. Also other studies have suggested that habitat selection by large mammal herbivores can be affected by landscape characteristics including proximity of more preferred vegetation $[53,15]$ or amount of edges between habitats [16]. It is likely that all these factors will have an influence but further work is needed to establish the detailed hierarchy of 
factors controlling local deer density in nonnative habitats.

\section{CONCLUSION}

In conclusion, we accept the first hypothesis that grasses form a major part of the diet of non-native UK sika deer throughout the year but reject the second hypothesis that the deer living in a mosaic of grassland, heathland and woodland habitats in southern England select grassland habitats above other habitats. This is because although our results support the general finding of studies of sika deer in their native habitat that grasses form a major part of their diet, they also show that, in the non-native environment studied, the strongest habitat selection was for heathland, the habitat that offers the least nutrient reward but which offers a source of roughage in the diet and some harbourage from human disturbance. This has implications for the conservation management of heathlands used by sika deer as it strongly indicates that heathland is a vulnerable habitat due to being favoured by sika deer but that its vulnerability can be reduced by more targeted action that manipulates the local density of deer use of any one area of heathland through well thought out habitat management actions such as increased disturbance or the removal of harbourage at the home range scale $(150-150$ ha) around sensitive areas. Furthermore, the findings of this study indicate that there is substantial potential for conservation managers to actively use managed numbers of wild sika as free conservation management tools for the control of tree encroachment and over dominating Molinia caerulea. We suggest that this approach of incorporation of established invasive species as tools into conservation management plans may be an approach worth considering in some of the many other scenarios where introduced species are too established for eradication to be a feasible way forward or where aiming for maintaining habitats using traditional domestic herbivore grazing techniques becomes an untenable conservation goal due to funding constraints, negative interactions with amenity use by people such as dog walking or other causes of environmental change.

\section{ACKNOWLEDGEMENTS}

We thank Mr Johnny O'Brien, the deer manager at Arne for his huge contribution to the study including leading capturing the deer for fitting radio collars and providing the rumen samples. We also thank Prof. Rory Putman for his very helpful advice to the project and thank the Royal Society for the Protection of Birds the Ministry of Defence and Natural England for funding to support this work.

\section{COMPETING INTERESTS}

Authors have declared that no competing interests exist.

\section{REFERENCES}

1. Sharp RL, Larson LR, Green GT. Factors influencing public preferences for invasive alien species management. Biological Conservation. 2011;144(8): 2097-2104.

2. Kettenring $\mathrm{KM}$, Adams CR. Lessons learned from invasive plant control experiments: A systematic review and meta-analysis. Journal of Applied Ecology. 2011;48(4):970-979.

3. Lambertini M, Leape J, Marton-Lefevre J, et al. Invasives: A major conservation threat. Science. 2011;333(6041):404-405.

4. Rodriguez LF. Can invasive species facilitate native species? Evidence of how, when, and why these impacts occur. Biological Invasions. 2006;8:927-939.

5. Carvalheiro LG, Barbosa ERM, Memmott J. Pollinator networks, alien species and the conservation of rare plants: Trinia glauca as a case study. Journal of Applied Ecology. 2008;45:1419-1427.

6. Davis NE, Forsyth DM, Coulson G. Facilitative interactions between an exotic mammal and native and exotic plants: Hog deer (Axis porcinus) as seed dispersers in south-eastern Australia. Biological Invasions. 2010;12(5):10791092.

7. Schlaepfer MA, Sax DF, Olden JD. The potential conservation value of non-native species. Conservation Biology. 2011; 25(3):428-437.

8. Whitehead GK. The deer of Great Britain and Ireland. London, Routledge \& Kegan Paul; 1964.

9. Coomes DA, Allen RB, Forsyth DM, Lee WG. Factors preventing the recovery of New Zealand forests following control of invasive deer. Conservation Biology. 2003;17(2):450-459.

10. Nentwig W, Kühnel E, Bacher S. A generic impact-scoring system applied to 
alien mammals in Europe. Conservation Biology. 2009;21(1):302-311.

11. Putman RJ, Moore NP. Impact of deer in lowland Britain on agriculture, forestry and conservation habitats. Mammal Review. 1998;28(4):141-164.

12. Kelly DL. (The regeneration of Quercus petraea (sessile oak) in southwest Ireland: A 25-year experimental study. Forest Ecology and Management. 2002; 166(1-3):207-226.

13. Tsujino R, Yumoto T. Effects of sika deer on tree seedlings in a warm temperate forest on Yakushima Island, Japan. Ecological Research. 2004;19(3):291-300.

14. Shibata E, Saito M, Tanaka M. Deer-proof fence prevents regeneration of Picea jezoensis var. hondoensis through seed predation by increased woodmouse populations. Journal of Forest Research. 2008;13(2):89-95:140(2):93-99.

15. Miyashita T, Suzuki M, Takada M, Fujita G, Ochiai K, Asada M. Landscape structure affects food quality of sika deer (Cervus nippon) evidenced by fecal nitrogen levels. Population Ecology. 2007; 49(3):185-190.

16. Miyashita T, Suzuki M, Ando D, Fujita G, Ochiai K, Asada M. Forest edge creates small-scale variation in reproductive rate of sika deer. Population Ecology. 2008; 50(1):111-120.

17. Takatsuki S. Use of mires and food habits of sika deer in the Oze Area, central Japan. Ecological Research. 2003;18(3): 331-338.

18. Takatsuki S. Food habits of sika deer on Mt. Goyo, northern Honshu. Ecological Research. 1986;1(2):119-128.

19. Asada M, Ochiai K. Food habits of sika deer on the Boso Peninsula, central Japan. Ecological Research. 1996;11(1): 89-95.

20. Yokoyama S, Koizumi T, Shibata E. Food habits of sika deer as assessed by faecal analysis in Mt. Ohdaigahara, central Japan. Journal of Forest Research. 1996; 1(3):161-164.

21. Borkowski J, Furubayashi K. Home range size and habitat use in radio-collared female sika deer at high altitudes in the Tanzawa Mountains, Japan. Ann. Zool. Fennici. 1998a;35(3):181-186.

22. Campos-Arceiz A, Takatsuki S. Food habits of sika deer in the Shiranuka Hills, eastern Hokkaido: A northern example from the north-south variations in food habits in sika deer. Ecological Research. 2005;20(2):129-133.

23. Kaji K, Miyaki M, Saitoh T, Ono S, Kaneko M. Spatial distribution of an expanding sika deer population on Hokkaido Island, Japan. Wildlife Society Bulletin. 2000; 28(3):699-707.

24. Weerasinghe UR, Takatsuki S. A record of acorn eating by sika deer in western Japan. Ecological Research. 1999;14(2): 205-209.

25. Jayasekara $P$, Takatsuki S. Seasonal food habits of a sika deer population in the warm temperate forest of the westernmost part of Honshu, Japan. Ecological Research. 2000;15(2):153-157.

26. Yokoyama M, Kaji K, Suzuki M. Food habits of sika deer and nutritional value of sika deer diets in eastern Hokkaido, Japan. Ecological Research. 2000;15(3): 345-355.

27. Takahashi H, Kaji K. Fallen leaves and unpalatable plants as alternative foods for sika deer under food limitation. Ecological Research. 2001;16(2):257-262.

28. Miyaki M, Kaji K. Summer forage biomass and the importance of litterfall for a highdensity sika deer population. Ecological Research. 2004;19(4):405-409.

29. Horwood MT, Masters EH. Sika deer. $2^{\text {nd }}$ (revised) edn. Hampshire: The British Deer Society; 1981.

30. Mann JCE, Putman R. Diet of British sika deer in contrasting environments. Acta Theriologica. 1989a;34(6):97-109.

31. Mann JCE, Putman RJ. Patterns of habitat use and activity in British populations of sika deer of contrasting environments. Acta Theriologica. 1989b; 34(5):83-96.

32. Putman RJ. Sika deer. Joint publication by The Mammal Society, London, and the British Deer Society, Hampshire; 2000.

33. Lever $C$. The naturalised animals of the British Isles. London: Hutchinson and Co. Ltd.; 1977.

34. Merrington G, Winder L, Green I. The uptake of $\mathrm{Cd}$ and $\mathrm{Zn}$ by the bird cherry oat aphid Rhopalosiphum padi (Homoptera: Aphididae) feeding on wheat grown on sewage sludge amended agricultural soil. Environmental Pollution. 1997;96:111-114.

35. Kenward RE, Walls SS, South AB, Casey NM. Ranges8: For the analysis of tracking and location data. Online Manual. Anatrack Ltd. Wareham UK.; 2008. 
36. Manly BFJ, McDonald LL, Thomas DL, McDonald TL, Erickson WP. Resource selection by animals: Statistical design and analysis for field studies. Second edition. Kluwer Academic Publishers, Boston, Massachusetts, USA; 2002.

37. Aebischer NJ, Robertson PA, Kenward RE. Compositional analysis of habitat use from animal radio-tracking data. Ecology. 1993;74(5):1313-1325.

38. Obrtel R, Holisova V, Kozena I. The winter diet of sika deer (Cervus nippon) in the Bouzovsko area. Folia Zool. 1985; 34(1):1-22.

39. Koga T, Ono $Y$. Sexual differences in foraging behaviour of sika deer, Cervus nippon. Journal of Mammalogy. 1994; 75(1):129-135.

40. Gates CC, Hudson RJ. Weight dynamics of wapiti in the boreal forest. Acta Theriologica. 1981;26:407-418.

41. Everitt JH, Gonzalez CL. Seasonal nutrient content in food plants of whitetailed deer on the South Texas Plains. Journal of Range Management. 1981; 34(6):506-510.

42. Jung HG, Allen MS. Characteristics of plant cell walls affecting intake and digestibility of forages by ruminants. Journal of Animal Science. 1995;73(9): 2774-2790.

43. Ichimura, $\mathrm{Y}$, Yamano, H, Takano $\mathrm{T}$, Koike S, Kobayashi Y, Tanaka K, Ozaki N, Suzuki M, Okada H, Yamanaka M. Rumen microbes and fermentation of wild sika deer on the Shiretoko peninsula of Hokkaido Island, Japan. Ecological Research. 2004;19(4):389-395.

44. Asano S, Ikeda S, Kurokawa Y, Kanda S, Itabashi H. Seasonal changes in digestibility, passage rate and rumen fermentation of alfalfa hay in sika deer (Cervus nippon) under restricted feeding. Animal Science Journal. 2007;78(1):2833.

45. McNaughton SJ. Grazing lawns: Animals in herds, plant form and coevolution. American Naturalist. 1984;124:863-886.

46. Ando M, Yokota HO, Shibata E. Bark stripping preference of sika deer, Cervus nippon, in terms of bark chemical contents. Forest Ecology and Management. 2003;177(1):323-331.

47. Ando M, Yokota HO, Shibata E. Why do sika deer, Cervus nippon, debark trees in summer on Mt. Ohdaigahara, central Japan? Mammal Study. 2004;29:73-83.

48. Miles J. Burning Molina dominant vegetation for grazing by red deer. Grass and Forage Science. 1971;26(4):247-250.

49. Gordon IJ. Facilitation of red deer grazing by cattle and its impact on red deer performance. Journal of Applied Ecology. 1988;25(1):1-9.

50. Borkowski J. Flight behaviour and observability in human-disturbed sika deer. Acta Theriologica. 2001;46(2):195206.

51. Hirth D. Social behaviour of white-tailed deer in relation to habitat. Wildlife Monographs. 1977;53:1-55.

52. Maeji I, Yokoyama S, Shibata E. Population density and range use of sika deer, Cervus nippon, on Mt. Ohdaigahara, Central Japan. Journal of Forest Research. 1999;4:235-239.

53. Palmer SCF, Hester AJ, Elston DA, Gordon IJ, Hartley SE. The perils of having tasty neighbors: Grazing impacts of large herbivores at vegetation boundaries. Ecology. 2003;84(11):28772890.

(c) 2017 Diaz et al.; This is an Open Access article distributed under the terms of the Creative Commons Attribution License (http://creativecommons.org/licenses/by/4.0), which permits unrestricted use, distribution, and reproduction in any medium, provided the original work is properly cited.

Peer-review history:

The peer review history for this paper can be accessed here: http://sciencedomain.org/review-history/22587 